\title{
Antimicrobials in acute exacerbations of chronic obstructive pulmonary disease - An analysis of the time to next exacerbation before and after the implementation of standing orders
}

\author{
Rob D Goddard BScPharm ${ }^{1}$, Shelly A McNeil MD², \\ Kathryn L Slayter PharmD ${ }^{1,2}$, R Andrew Mclvor MD MSc FRCP ${ }^{3}$
}

RD Goddard, SA McNeil, KL Slayter, R McIvor. Antimicrobials in acute exacerbations of chronic obstructive pulmonary disease - An analysis of the time to next exacerbation before and after the implementation of standing orders. Can J Infect Dis 2003;14(5):254-259.

OBJECTIVE: To compare the mean time to next exacerbation in patients with acute exacerbations of chronic obstructive pulmonary disease (COPD) before and after the implementation of standing orders.

SETTING: Tertiary care hospital, Halifax, Nova Scotia, Canada. POPULATION STUDIED: The records of 150 patients were analyzed, 76 were in the preimplementation group, 74 in the postimplementation group.

INTERVENTION: The management and outcomes of patients admitted with an acute exacerbation of COPD before and after the implementation of standing orders were compared.

DESIGN: A retrospective chart review.

MAIN RESULTS: There was no difference in the mean time to next exacerbation between treatment groups (preimplementation group: 310 days, postimplementation group: 289 days, $\mathrm{P}=0.53$ ) Antibiotics were used in $90 \%$ of the cases (preimplementation group: $87 \%$, postimplementation group: $93 \%$ ). The postimplementation group had a $20 \%$ increase in the use of first-line agents over the preimplementation group. Overall, first-line agents represented only $37 \%$ of the antibiotic courses.

CONCLUSIONS: The implementation of standing orders encouraged the use of first-line agents but did not influence subsequent symptom resolution, length of hospital stay, or the infection-free interval in patients with acute exacerbations of COPD.
Efficacité des antimicrobiens dans les exacerbations de bronchopneumopathie chronique obstructive : étude du temps écoulé avant l'apparition de l'épisode suivant, avant et après l'application de consignes.

OBJECTIF : Comparer le temps moyen écoulé avant l'apparition de l'épisode suivant de bronchopneumopathie chronique obstructive (BPCO), avant et après l'application de consignes.

LIEU : Hôpital de soins tertiaires, Halifax.

POPULATION À L'ÉTUDE : Ont été examinés les dossiers de cent cinquante patients : 76 avant l'application; 74 , après.

INTERVENTION : Nous avons comparé le traitement de patients admis pour une exacerbation de BPCO et les résultats obtenus, avant et après l'application des consignes.

TYPE D'ÉTUDE : Examen rétrospectif de dossiers.

PRINCIPAUX RÉSULTATS : Aucune différence n'a été observée entre les deux groupes quant au temps moyen écoulé avant l'exacerbation suivante (avant l'application : 310 jours; après l'application : 289 jours; $p=0,53$ ). Des antibiotiques ont été prescrits dans $90 \%$ des cas (avant l'application : $87 \%$; après l'application : $93 \%$ ). Une augmentation de $20 \%$ de l'utilisation des médicaments de première intention a été notée dans le groupe de post-intervention par rapport au groupe de pré-intervention. Dans l'ensemble, ces derniers médicaments ne constituaient que $37 \%$ des cures d'antibiotiques.

CONCLUSION : L'application des consignes a favorisé le recours aux médicaments de première intention mais n'a pas eu d'incidence sur la disparition ultérieure des symptômes, la durée du séjour à l'hôpital ou le temps écoulé sans infection chez les patients atteints d'une exacerbation de BPCO.

Key words: Antibiotics; Chronic obstructive pulmonary disease; Exacerbation

In Canada, chronic obstructive pulmonary disease (COPD) is a major health issue affecting over 750,000 people and the fourth ranked cause of mortality $(1,2)$. Worldwide, it is the second most common chronic noncommunicable disease and the only leading cause of death that is increasing in prevalence $(1,3,4)$. The inpatient mortality associated with COPD exacerbations ranges from 3\% to 4\% (5). Each year, over 52,000 hospital admissions and 16,000 deaths in Canada are attributed to COPD $(1,6)$. At our institution, Queen Elizabeth II Health
Sciences Centre, COPD exacerbations are the third leading cause for admissions to the internal medicine service (preceded by pneumonia and congestive heart failure) (7).

In patients with COPD, acute infectious exacerbations are the most common precipitating factor leading to hospitalization and the most common cause of death (8-10). Up to $80 \%$ of acute exacerbations of COPD are due to respiratory infections, with $50 \%$ to $70 \%$ of these caused by bacteria and only $10 \%$ to $30 \%$ caused by viruses (11-13). In September 2000, standing

Departments of ${ }^{1}$ Pharmacy, ${ }^{2}$ Infectious Diseases and ${ }^{3}$ Respirology, Queen Elizabeth II Health Sciences Centre, Halifax, Nova Scotia

Correspondence: Rob D Goddard, Pharmacy Department, Queen Elizabeth Hospital, Provincial Health Services Authority, 60 Riverside Drive,

Charlottetown, Prince Edward Island C1A 8T5. Telephone 902-894-2974, fax 902-894-2911, e-mail rdgoddard@ihis.org

Received for publication November 27, 2002. Accepted May 16, 2003 
orders for patients with a COPD exacerbation were implemented at our institution (Figures 1 and 2), with the rationale that prompt institution of optimal care, including controlled oxygenation and maximum bronchodilation, anti-inflammatory, and antibiotic therapy, would improve outcomes. The antibiotic choice included as first-line agents were trimethoprim/sulfamethoxazole (TMP/SMX) and doxycycline hyclate. Second-line agents were azithromycin dihydrate, amoxicillin trihydrate/clavulanate pottasium, cefuroxime sodium, and ciprofloxacin. It was our intent to assess the impact of these orders on clinical outcome (time to next exacerbation, clinical symptomatology), antimicrobial outcome (culture eradication), and resource utilization (antimicrobial use) via a quality assurance retrospective chart review.

\section{METHODS}

\section{Objectives}

Our primary objective was to determine the time to next exacerbation in a population of patients with COPD admitted to the institution before and after the implementation of standing orders. Secondary objectives included comparing the clinical and microbiological outcomes of patients in both treatment groups, analyzing and comparing the use of antibiotics in the treatment groups, and comparing the time to next exacerbation with the type of antibiotic class. Our hypothesis was that the time to next exacerbation differed by at least 21 days in patients with an acute exacerbation of COPD between pre- and postimplementation of standing orders. The 'preimplementation' group consisted of patients admitted between September 1999 and August 2000; the 'postimplementation' group consisted of patients admitted between September 2000 and August 2001. Patients with COPD exacerbations as their major reason for admission were identified from a database maintained by the Division of Respirology at Queen Elizabeth II Health Sciences Centre. The Research Ethics Board approved the study protocol via an expedited review.

\section{Patients}

In order to prevent bias, hospital unit numbers (HUNs) were randomly chosen from the database and, where applicable, assigned to either the pre- or postimplementation group. A total of 832 patients were randomized, 682 of which were excluded for various protocol violations. Patients with Anthonisen Type-III exacerbations were excluded as antibiotic use is not advocated in this population (11). Other exclusion criteria included a diagnosis of asthma or pneumonia, a history of cystic fibrosis or lung carcinoma, or the concomitant use of an antibiotic for another indication.

The Medical Records Department retrieved the charts from the defined randomized list. Over a six-week period (March 2002 to April 2002) a retrospective chart review and data extraction was conducted. Patient data were reviewed for a minimum of nine months to identify the date of the next exacerbation. Subsequent exacerbations were limited to patients who either were admitted to or visited the emergency department of the Queen Elizabeth II Health Sciences Centre. The chart analysis included the collection of baseline characteristics of each patient including age, gender, concomitant disease status, smoking status, pulmonary function tests, antibiotic usage, and steroid usage.

\section{Statistics}

Data were compared by Student's $t$ test, $\chi^{2}$ test, Fisher's exact test, and Log-rank test, where appropriate. $95 \%$ Confidence Interavals
(95\% CIs) were recorded and all P-values were judged to be significant if the result of a two-sided test was less than 0.05. Patients were censored nine months following the acquisition period.

A clinically significant difference between treatment groups was measured as time to next exacerbation. Using a two-tailed alpha of 0.05 and power of 0.8 , the required sample to detect a difference between 150 days and 171 days was determined to be 57 patients per group. Accounting for invalid patients, the study required 74 patients per arm, for a total of 148 patients.

\section{Patient demographics}

\section{RESULTS}

Demographic and clinical characteristics were similar between treatment groups (Table 1). Based on forced expiratory volume in 1 second $\left(\mathrm{FEV}_{1}\right)$ data, the majority of patients presented with a severe COPD disease state, while slightly more patients presented with a moderate exacerbation. Patients in the preimplementation group had fewer exacerbations during the preceding year, however, this result was not statistically significant $(P=0.69)$. In keeping with recent epidemiology of the changing face of COPD, this group is predominately female $(61 \%)$.

\section{Infection free interval}

A total of 208 exacerbations (150 initial, 58 subsequent) were recorded. Within the patient group experiencing a subsequent exacerbation, the mean time to next exacerbation was $132 \pm 15$ days $(\mathrm{n}=58)$. Patients in the preimplementation group had an infection-free interval of $134 \pm 21$ days $(n=28)$, the same was seen for the postimplementation group $(130 \pm 21$ days $[\mathrm{n}=30]$, a nonsignificant difference $[\mathrm{P}=0.89])$.

A Kaplan-Meier survival curve was conducted for an analysis of exacerbation events in the overall population (Figure 3). The mean time to next exacerbation was $304 \pm 13$ days. There was no difference in the overall mean time to next exacerbation (preintervention $310 \pm 18$ days, postintervention $289 \pm 18$ days, $\mathrm{P}=0.53$ ). The estimated probability that a patient will be exacerbation-free for 365 days or more is $63 \pm 4 \%$.

\section{Clinical outcomes}

Overall symptom resolution, defined as a return to baseline of all Anthonisen symptoms (increased dyspnea, sputum volume, and sputum purulence), was recorded $(n=52)$. A $7 \%$ relative increase in symptom resolution was observed in the postimplementation group, this result, however, was not statistically significant $(59 \%$ versus $63 \%, P=1.0)$. The length of stay was longer in the postimplementation group $(10.8 \pm 0.58$ days versus $8.6 \pm 1.14$ days), but was not statistically significant $(\mathrm{P}=0.08)$ (Table 2).

\section{Medication use}

Ninety per cent of the patients received a course of antibiotics (87\% preintervention, 93\% postintervention, $\mathrm{P}=0.30$ ). Antibiotics were initiated within the first $24 \mathrm{~h}$ in $90 \%$ of these cases. One hundred seventy-two courses of antibiotics were ordered using 14 different antibiotics. Cefuroxime sodium, doxycycline hyclate, levofloxacin and TMP/SMX represented $77 \%$ of the antibiotic utilization. Levofloxacin, cefuroxime sodium and TMP/SMX were used more frequently in the preimplementation group (30\%, 22\% and $22 \%$ respectively) than in the postimplementation group $(18 \%, 12 \%$ and $11 \%$, respectively), which trended towards significance $(\mathrm{P}=0.09)$. In 


\section{Physician Standing Orders \\ Department of Medicine \\ Admission Standing Orders \\ Diagnosis: Exacerbation of COPD}

Patient:

Allergies

Smoking Status:

Date (YYYY/MM/DD)

Time (24h/hh:mm)

1. The following orders may be used in any patient care area.

2. The following orders will be carried out by a qualified Nurse/Health Care Professional ONLY on the AUTHORITY OF A PHYSICIAN.

3. All orders to be carried out must be checked as appropriate.

4. Nutrition

$\square$ Diet_ $\quad \square \mathrm{Ht}$ and $\mathrm{Wt}$

$\square$ Nutrition consult $\quad$ RMO $\square$ yes $\square$ no

5. Mobility

$\square$ Activity

$\square$ Consult Physiotherapy RMO $\square$ yes $\square$ no

6. Vital Signs

$\square$ Temp, HR, RR, BP, QID x 48h , then reassess

$\square$ Other

7. Chemstrips

$\square$ If known diabetes, do chemstrip (ac \& qhs)

$\square$ If no known diabetes BID $\times 48 \mathrm{~h}$ then reassess

$\square$ Contact MD if chemstrip $<4 \mathrm{mmol} / \mathrm{L}$ or $>$ $15 \mathrm{mmol} / \mathrm{L}$

8. Investigations

$\square$ Sputum C\&S and Gram stain

$\square$ Spirometry (admission and within $48 \mathrm{~h}$ of discharge)

9. Oxygen Therapy

$\square$ Nasal prongs (uncontrolled FiO2) @ $\mathrm{L} / \mathrm{min}$

OR

If hypercapnic, Venturi Mask (Controlled FiO2) $\mathrm{FiO} 2 @ \square 0.24 \square 0.28 \square$

To keep $\mathrm{O} 2$ saturation at:

$\square 85 \%-88 \%$ or $\square 88 \%-92 \%$

$\square \mathrm{ABG} @$ (time)

$\square \mathrm{O} 2$ saturation in $\mathrm{h}$

$\square \mathrm{O} 2$ saturation daily

Date: (YYYY/MM/DD)

License Number

QE8020 07/00
10. MEDICATIONS

(a) Bronchodilators

MDI with spacer

$\square$ Ipratropium Bromide 4 puffs $\mathrm{q} 4 \mathrm{~h} \times 48 \mathrm{~h}$ then reassess

$\square$ Salbutamol 4 puffs $\mathrm{q} 4 \mathrm{~h} \times 48 \mathrm{~h}$ then reassess

$\square$ Salbutamol 4 puffs q2h PRN

Wet Nebulizer

\section{OR}

$\square$ Ipratropium Bromide $0.5 \mathrm{mg}$ q4h $\times 48 \mathrm{~h}$ then reassess

$\square$ Salbutamol $5 \mathrm{mg} \mathrm{q} 4 \mathrm{~h} \times 48 \mathrm{~h}$ then reassess

$\square$ Salbutamol $5 \mathrm{mg}$ q2h PRN

$\square$ Salbutamol $2.5 \mathrm{mg}$ q2h PRN

(b) Steroid Therapy

$\square$ Prednisone OR mg po daily

$\square$ Methylprednisolone mg IV q _ $\mathrm{h}$

(c) Antimicr obials (Calculate $\mathrm{CrCl}$-see reverse) (If chest $x$-ray indicates pneumonia, start CAP Pathway and choose antimicrobials from the pathway)

If 2 of the following, use antimicrobials: Increased dyspnea Increased sputum volume Increased sputum purulence

$\square$ TMP-Sulfa DS 1 tab po BID $\times 10$ days

$\square$ Doxycycline $200 \mathrm{mg}$ po stat then $100 \mathrm{mg}$ po BID $\mathrm{x}$ 10 days (with a full glass of water and sit up $\times 1 \mathrm{~h}$ ) (For 3 or more exacerbations of COPD in the last year or use of antimicrobials in the last 30 days for a respiratory infection, consider a second line antimicr obial)

$\square$ Second line oral antimicrobial agent (see reverse)

11. $\square$ Consult COPD Case Management Coordinator

12. Code Status ("Full code" if there is no order)

Physician's Signature

Physician's Name-Print

Page 1 of 2

Figure 1) Physician standing orders for acute exacerbations of chronic obstructive pulmonary disease (COPD) implemented at the Queen Elizabeth II Health Sciences Centre in September 2000 - front page, emphasizing use of first-line antibiotics. ABG Arterial blood gas; ac Before meals; BID Twice a day; BP Blood pressure; CESS Culture and sensitivity; $\mathrm{CAP}$ Community-acquired pneumonia; $\mathrm{CrCl} \mathrm{Creatinine} \mathrm{clearance;} \mathrm{FiO} 2$ Fraction of inspired oxygen; Ht Height; HR Heart rate; IV Intravenous; MDI Metered dose inhaler; PRN As required; RMO Requisition made out; RR Rate of respiration; Wt Weight 
contrast, there was a statistically significant increase $(\mathrm{P}<0.01)$ in the frequency of doxycycline hyclate use in the postimplementation group (35\%) compared to the preimplementation group (5\%). Overall, second-line agents were used more frequently than first-line agents (54\% versus 37\%). There was a $20 \%$ increase in the use of first-line agents in the postimplementation group $(\mathrm{P}=0.01)$ (Figure 4$)$.

Systemic corticosteroids were used in $95 \%$ of the patients, with no significant difference between treatment groups with regard to their use $(\mathrm{P}=0.75)$; however, there was a difference with regard to dosage formulation. Patients in the preimplementation group were more likely to receive intravenous steroids than oral steroids (61\% versus $39 \%, \mathrm{P}=0.03$ ), while the reverse was true for the postimplementation group.

\section{Microbiological data}

Sputum cultures were obtained more often at baseline in the postimplementation group ( $78 \%$ versus $42 \%, \mathrm{P}<0.01)$. Only 15 positive cultures (five preimplementation, 10 postimplementation) were obtained, identifying 21 potential pathogens (seven preimplementation, 14 postimplementation) of which 17 were bacterial and four fungal. Pseudomonas aeruginosa, Streptococcus pneumoniae, Haemophilus influenzae, and Staphyloccocus aureus accounted for $82 \%$ of the bacteria identified (Table 3 ).

\section{DISCUSSION}

Prolongation of the time to the next exacerbation is a secondary outcome of many recent COPD trials. The implementation of our standing orders did not influence the infection-free interval or time to symptom resolution. Although there was a slightly shorter infection-free interval in the postimplementation group, it was not a significant difference over the preimplementation group. This demonstrates that despite the more standardized global, patient-focused approach to treating acute exacerbations of COPD, the overall effects of the therapeutic choices within the standing order are neither beneficial nor detrimental with regard to patient outcomes.

\section{Factors Leading to Admission}

\#1 Acute deterioration of COPD $\square$.

\#2 Inadequate response of symptoms to outpatient management $\square$.

\#3 Unable to cope with prescribed medical management $\square$

\#4 Lack of community resources. Consider referral to HCNS $\square$.

\#5 Placement issues. Consider referral to Social Work $\square$

\#6 Financial issues. Consider referral to Social Work $\square$

\#7 Conclusion by Emergency Physician or Discharge Planning Nurse patient cannot manage at home with supplementar y home care Nurse patient cannot manage at hom
resources not immediately available

\#8 Other

TABLE 1

Patient demographics

\begin{tabular}{|c|c|c|c|c|}
\hline Characteristic & $\begin{array}{c}\text { Overall } \\
n=150(\%)\end{array}$ & $\begin{array}{c}\text { Pre-implementation } \\
n=76(\%)\end{array}$ & $\begin{array}{l}\text { Post-implementation } \\
\text { n=74 (\%) }\end{array}$ & P-value* \\
\hline Mean age in years \pm sd & $73 \pm 1$ & $72 \pm 1$ & $74 \pm 1$ & $0.22^{\dagger}$ \\
\hline Female & $91(61)$ & $46(61)$ & $45(61)$ & 1 \\
\hline Male & $59(39)$ & $30(39)$ & $29(39)$ & - \\
\hline Smoking status $(n=145)$ & & & & - \\
\hline Active & $59(41)$ & $36(47)$ & $23(31)$ & $0.95^{\dagger}$ \\
\hline Former & $78(54)$ & $33(43)$ & $45(61)$ & $0.21^{\dagger}$ \\
\hline Never & $8(5)$ & $6(8)$ & $2(3)$ & - \\
\hline Coronary artery disease & $59(39)$ & $28(37)$ & $31(42)$ & 0.59 \\
\hline Congestive heart failure & $39(26)$ & $19(25)$ & $20(27)$ & 0.88 \\
\hline Diabetes mellitus & $35(23)$ & $21(28)$ & $14(19)$ & 0.29 \\
\hline Anthonisen's Criteria & & & & - \\
\hline Type I exacerbation & $67(45)$ & $35(46)$ & $32(43)$ & - \\
\hline Type II exacerbation & $83(55)$ & $41(54)$ & $42(57)$ & - \\
\hline $\mathrm{FEV}_{1}$ on admission $(\mathrm{n}=80)$ & & & & 0.29 \\
\hline$<35 \%$, severe impairment & $57(38)$ & $28(37)$ & $29(39)$ & - \\
\hline $35-49 \%$, moderate impairment & $15(10)$ & $7(9)$ & $8(11)$ & - \\
\hline$\geq 50 \%$, mild impairment & $8(5)$ & $6(8)$ & $2(3)$ & - \\
\hline No prior exacerbations ${ }^{\ddagger}$ & $76(51)$ & $41(54)$ & $35(47)$ & 0.62 \\
\hline$>3$ prior exacerbations & $9(6)$ & $3(4)$ & $6(8)$ & - \\
\hline
\end{tabular}

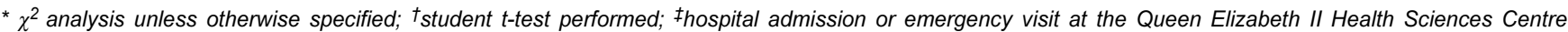
Anthonisen's Criteria: Type I exacerbation - all three symptoms of increased dyspnea, increased sputum volume and increased sputum purulence; Type II exacerbation - two of the three clinical symptoms. FEV ${ }_{1}$ Forced expiratory volume in 1 second 


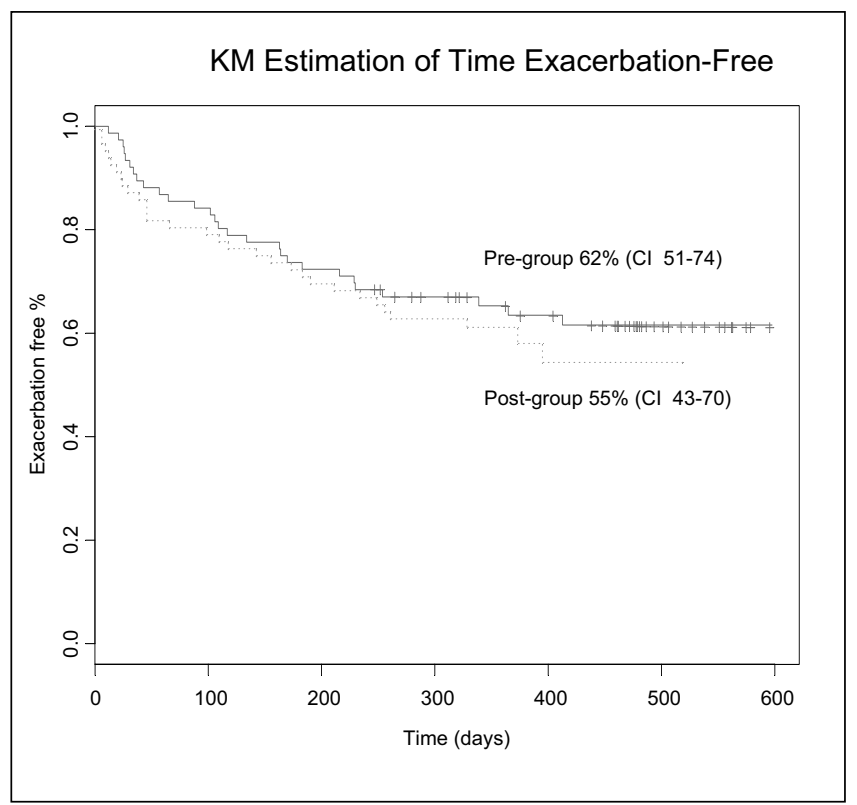

Figure 3) Kaplan Meier (KM) analysis of the time to next exacerbation. The top line (solid) represents the estimate of infection-free interval of the preimplementation group. The bottom line (dashed) represents that of the postimplementation group

TABLE 2

\section{Clinical results}

\begin{tabular}{lcccc}
\hline $\begin{array}{l}\text { Variable } \\
\text { (mean } \pm \text { SD) }\end{array}$ & Overall & $\begin{array}{c}\text { Pre- } \\
\text { implementation }\end{array}$ & $\begin{array}{c}\text { Post- } \\
\text { implementation }\end{array}$ & $\begin{array}{c}\text { P } \\
\text { value }\end{array}$ \\
\hline Length of & $9.7 \pm 0.6$ & $8.6 \pm 1.1$ & $10.8 \pm 0.6$ & 0.08 \\
stay & $132.2 \pm 14.9$ & $134.3 \pm 21.0$ & $130.3 \pm 21.4$ & 0.89 \\
$\begin{array}{l}\text { Days between } \\
\text { exacerbation* }\end{array}$ & $303.6 \pm 12.6$ & $309.7 \pm 17.5$ & $288.9 \pm 17.8$ & $0.53^{\ddagger}$ \\
$\begin{array}{l}\text { Days to next } \\
\text { exacerbation }\end{array}$ & & & & \\
\hline
\end{tabular}

*subgroup of patients with a subsequent exacerbation ( $n=58) ;{ }^{\dagger}$ estimate of the overall study population; ${ }^{\ddagger}$ Log-Rank test

Treating exacerbations of COPD with antibiotics has been an area of controversy over the past 40 years. Since the 1960 s, there have been several placebo-controlled trials analyzing the efficacy of antibiotics in COPD exacerbations. Seven trials analyzing similar antibiotics as those commonly prescribed at this institution have demonstrated an overall benefit for the patient $(11,14-19)$. Albeit small, this benefit was reinforced by two meta-analyses of 11 randomized, placebo-controlled trials by Saint et al in 1995 (20) and McCrory (21). These analyses, however, had difficulty accounting for heterogeneity between trials as there has been a lack of consensus regarding the description of a COPD exacerbation as well as the use of concomitant medications. Variable rating systems and ever-changing outcome measures between trials further challenge the notion of antibiotic use. Although not conclusively demonstrated, it is clear that patients who present with evidence of a bacterial infection with moderate to severe exacerbations (Anthonisen Type-I or Type-II) benefit from antibiotics. The use of antibiotics is reinforced by various sets of national consensus guidelines (3,4,6,21-26). Canadian anti-infective guidelines have also encouraged risk stratification, suggesting certain individuals in whom it would be more appropriate to commence therapy with a second-line antibiotic (25).

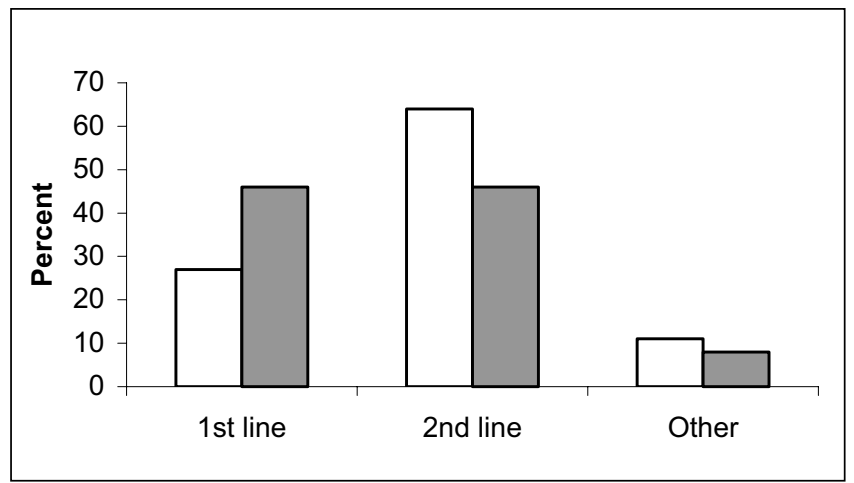

Figure 4) Per cent of antibiotics used during the study, grouped according to antibiotic class. The white bar represents the preimplementation group while the dark bar represents the postimplementation group. First-line antibiotics included trimethoprim/sulfamethoxazole and doxycycline hyclate. Second-line antibiotics included azithromycin dihydrate, amoxicillin trihydrate/clavulanate potassium, cefuroxime sodium and ciprofloxacin

\section{TABLE 3}

Microbiological results

\begin{tabular}{llcc}
\hline $\begin{array}{l}\text { Positive culture } \\
\text { organism identified }\end{array}$ & $\begin{array}{c}\text { Overall } \\
\mathbf{n = 2 1}(\%)\end{array}$ & $\begin{array}{c}\text { Pre- } \\
\text { implementation } \\
\mathbf{n = 7}(\%)\end{array}$ & $\begin{array}{c}\text { Post- } \\
\text { implementation } \\
\mathbf{n = 1 4}(\%)\end{array}$ \\
\hline $\begin{array}{l}\text { Pseudomonas } \\
\text { aeruginosa }\end{array}$ & $4(19)$ & - & $4(29)$ \\
$\begin{array}{l}\text { Haemophilus } \\
\text { influenzae }\end{array}$ & $3(14)$ & - & $3(21)$ \\
$\begin{array}{l}\text { Streptococcus } \\
\text { pneumoniae } \\
\begin{array}{l}\text { Staphylococcus } \\
\text { aureus }\end{array}\end{array}$ & $4(19)$ & - & $4(29)$ \\
Other* & $2(10)$ & $2(29)$ & - \\
\hline
\end{tabular}

*includes methicillin-resistant Staphylococcus aureus, Serratia marcescens, Stenotrophomonas maltophilia, Group B-hemolytic streptococcus species, and Candida albicans

The use of antibiotics in acute exacerbations of COPD has become a standard of practice; what is not clear is which antibiotics should be used and when. This uncertainty continues because studies have not clearly demonstrated the benefit of newer antibiotics over older antibiotics (27). The present study was not powered to evaluate such a question but it does perpetuate the question at hand: does the specific antibiotic or antibiotic class affect patient outcome?

Despite the general agreement that antibiotics should be a part of the management of patients with acute exacerbations of COPD, $10 \%$ of patients in this study did not receive an antibiotic. This rate was not significantly different in the postimplementation group ( $13 \%$ versus $7 \%, \mathrm{P}=0.19)$.

There were several discrepancies in antibiotic use between treatment groups, an obvious reflection of the impact of the standing orders. First-line agents were used more frequently in the postimplementation group, a direct result of the $87 \%$ increase in doxycycline hyclate use. The use of levofloxacin, the drug of choice before the implementation of the standing orders, decreased by $36 \%$. The continued use of this antibiotic may be due, in part, to the growth of knowledge in regard to the 'respiratory quinolones' over the past several years. 
Interestingly, in the subgroup of patients with a subsequent exacerbation, levofloxacin (a second-line fluroquinolone antibiotic) was the antibiotic most frequently used in the preimplementation group, with a relative difference of $40 \%$. One would expect that if this antibiotic, or class of antibiotic, was superior to others, as demonstrated by Wilson et al (28), fewer patients in the preimplementation group would have subsequently had another exacerbation within the follow-up period. Another interesting finding from this subgroup was that patients with a subsequent exacerbation were more likely to have received a second-line agent during their initial exacerbation, regardless of treatment group. This finding is contradictory to a retrospective analysis (29) that demonstrated that antibiotic selection is not an independent risk factor for clinical failure.

The standing orders have had a dramatic impact on antibiotic use, apparent in the postimplementation subgroup. Within this group of 74 patients, physicians were more likely to prescribe doxycycline hyclate if the orders were implemented. If not implemented, $500 \mathrm{mg}$ of levofloxacin once daily was the antibiotic of choice. It is apparent that the standing orders for acute exacerbations of COPD streamline the use of antibiotics. However, the effects of this antibiotic rationalization on patient outcome is unclear.

Organisms identified from sputum cultures were in keeping with expectations, however, the variance in the distribution of organisms among treatment groups is puzzling. In the

\section{REFERENCES}

1. Lacasse Y, Brooks D, Goldstein RS, et al. Trends in the epidemiology of COPD in Canada, 1980 to 1995. Chest 1999;116:306-13.

2. Statistics Canada, Health Statistics Division. 1997 data. $<$ www.statcan.ca/english/Pgdb/health36.htm > (Version current at September 18, 2003).

3. Bach PB, Brown C, Gelfand SE, et al. Management of acute exacerbations of chronic obstructive pulmonary disease: A summary and appraisal of published evidence. Ann Intern Med 2001;134:600-20

4. Canadian Thoracic Society Workshop Group. Guidelines for the assessment and management of chronic obstructive pulmonary disease. CMAJ 1992;147:420-8.

5. Mushlin AI, Black ER, Connolly CA, et al. The necessary length of hospital stay for chronic pulmonary disease. JAMA 1991;266:80-3.

6. Pauwels RA, Buist AS, Calverley PMA, et al. Global strategy for the diagnosis, management, and prevention of chronic obstructive pulmonary disease: NHLBI/WHO Global initiative for chronic obstructive lung disease (GOLD) workshop summary. Am J Respir Crit Care Med 2001;163:1256-76.

7. Borzecki AM. COPD: Overview and drug treatment of acute exacerbations. Drugs Ther Mar Prac 2001;24:13-7.

8. Seemungal TAR, Donaldson GC, Bhowmik A, et al. Time course and recovery of exacerbations in patients with chronic obstructive pulmonary disease. Am J Respir Crit Care Med 2000;161:1608-13.

9. Sethi S. Infectious etiology of acute exacerbations of chronic bronchitis. Chest 2000;117(Suppl 2):S380-5.

10. Chodosh S, McCarty J, Farkas S, et al. Randomized, double-blind study of ciprofloxacin and cefuroxime axetil for treatment of acute bacterial exacerbations of chronic bronchitis. Clin Infect Dis 1998;27:722-9

11. Anthonisen NR, Manfreda J, Warren CPW, et al. Antibiotic therapy in exacerbations of chronic obstructive pulmonary disease. Ann Intern Med 1987;106:196-204.

12. Guthrie R. Community-acquired lower respiratory tract infections: Etiology and treatment. Chest 2001;120:2021-34

13. Wilson R. The role of infection in COPD. Chest 1998;113(Suppl 4):S242-S248

14. Allegra L, Blasi F, Bernardi B, et al. Antibiotic treatment and baseline severity of disease in acute exacerbations of chronic bronchitis: A re-evaluation of previously published data of a placebocontrolled randomized study. Pulm Pharmacol Ther 2001; $14 ; 149-55$

15. Elmes PC, King K, Langlands JH, et al. Value of ampicillin in the hospital treatment of exacerbations of chronic bronchitis. BMJ 1965;5467:904-8. postimplementation group, Pseudomonas aeruginosa was present in almost $30 \%$ of the cultures, whereas it was not present in the preimplementation group. Caution should be used in extrapolating these findings because only 15 samples were positive and we were not able to distinguish between colonizer and pathogen. Furthermore, current practice does not advocate obtaining a repeat culture, especially if the patient is clinically improving.

As with any study, there are limitations. Because it was a retrospective study we were unable to accurately account for antibiotic use before admission to hospital. This is important because it could influence the initial antibiotic used upon admission, and therefore, would provide additional insight into the general health of the patient and any possible resistant organisms he or she may be harboring. Patients' subsequent exacerbations were only accounted for if they returned to our institution, therefore transient patients or patients who sought medical attention elsewhere were not captured. The largest limitation of the study is that it only analyzes a subsection of a comprehensive treatment protocol affecting clinical outcomes in patients with exacerbations of COPD.

ACKNOWLEDGEMENTS: The authors thank Joanne Douglas and Kara Thompson for the database and statistical support, and Mary Harris, Case Management Coordinator, for her assistance, along with the Nova Scotia Lung Association for their Legacy Grant 2002.

16. Jørgensen AF, Coolidge J, Pedersen PA, et al. Amoxicillin in treatment of acute uncomplicated exacerbations of chronic bronchitis: A double-blind, placebo-controlled multicentre study in general practice. Scand J Prim Health Care 1992;10:7-11.

17. Nicotra MB, Rivera M, Awe RJ. Antibiotic therapy of acute exacerbations of chronic bronchitis: A controlled study using tetracycline. Ann Intern Med 1982;97:18-21.

18. Pines A, Raafat H, Greenfield JSB, et al. Antibiotic regimens in moderately ill patients with purulent exacerbations of chronic bronchitis. Br J Dis Chest 1972;66:107-15.

19. Sachs APE, Koëter GH, Groenier KH, et al. Changes in symptoms, peak expiratory flow, and sputum flora during treatment with antibiotics of exacerbations in patients with chronic obstructive pulmonary disease in general practice. Thorax 1995;50:758-63.

20. Saint S, Bent S, Vittinghoff, et al. Antibiotics in chronic obstructive pulmonary disease exacerbations: A meta-analysis. JAMA 1995:273:957-60.

21. McCrory DC, Brown C, Gelfand S, et al. Management of acute exacerbations of COPD: A summary and appraisal of published evidence. Chest 2001;119:1190-209.

22. American Thoracic Society. Standards for the diagnosis and care of patients with chronic obstructive pulmonary disease. Am J Respir Crit Care Med 1995;152(Suppl 2):S77-120.

23. The COPD Guidelines Group of the Standards of Care Committee of the BTS. BTS guidelines for the management of chronic obstructive pulmonary disease. Thorax 1997;52(Suppl 5):S1-28

24. Snow V, Lascher S, Mottur-Pilson C. Evidence base for management of acute exacerbations of chronic obstructive pulmonary disease. Ann Intern Med 2001;134:595-9.

25. Balter MS, Ryland RH, Low DE, et al. Recommendations on the management of chronic bronchitis: A practical guide for Canadian physicians. CMAJ 1994;151(Suppl 10):S8-S23.

26. Siafakas NM, Vermeire P, Pride NB, et al. Optimal assessment and management of chronic obstructive pulmonary disease (COPD). Eur Respir J 1995;8:1398-420.

27. Madaras-Kelly KJ, Magdanz SB, Johnson CK, et al. Clinical outcomes of ambulatory acute exacerbations of chronic bronchitis with older versus newer antimicrobials. Ann Pharmacother 2002;36:975-80.

28. Wilson R, Schentag JJ, Ball P, et al. A comparison of gemifloxacin and clarithromycin in acute exacerbations of chronic bronchitis and long-term clinical outcomes. Clin Ther 2002;24:639-52.

29. Dewan NA, Rafique S, Kanwar B, et al. Acute exacerbations of COPD: Factors associated with poor treatment outcome. Chest 2000;117:662-71. 


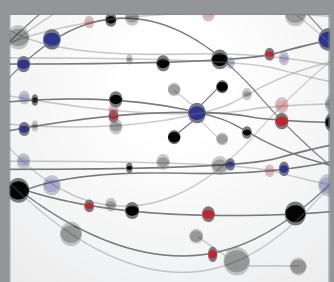

The Scientific World Journal
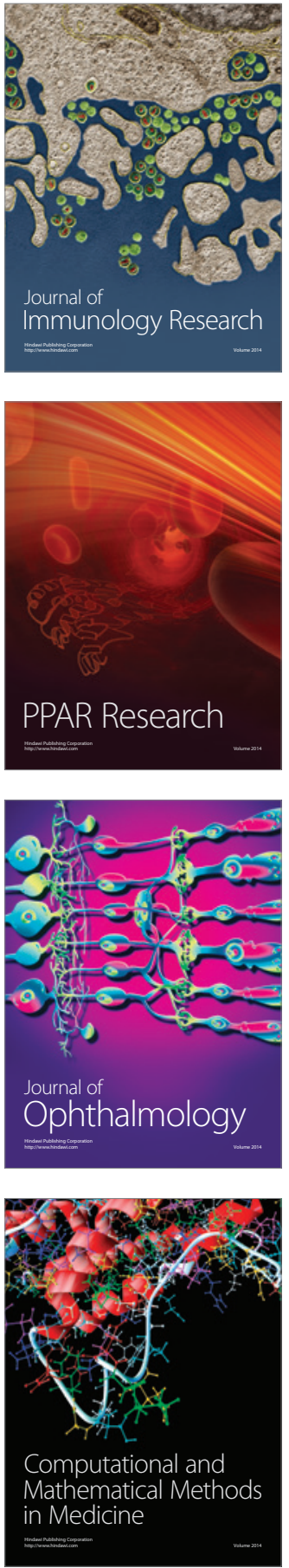

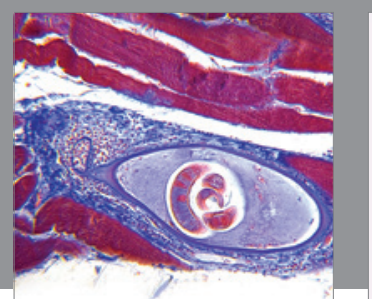

Gastroenterology Research and Practice

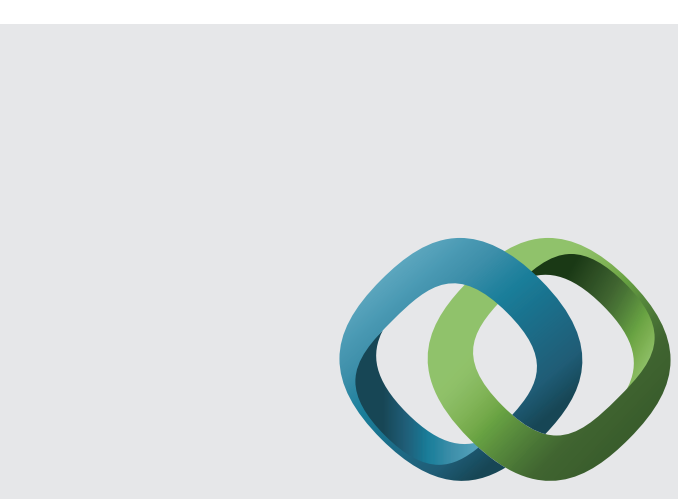

\section{Hindawi}

Submit your manuscripts at

http://www.hindawi.com
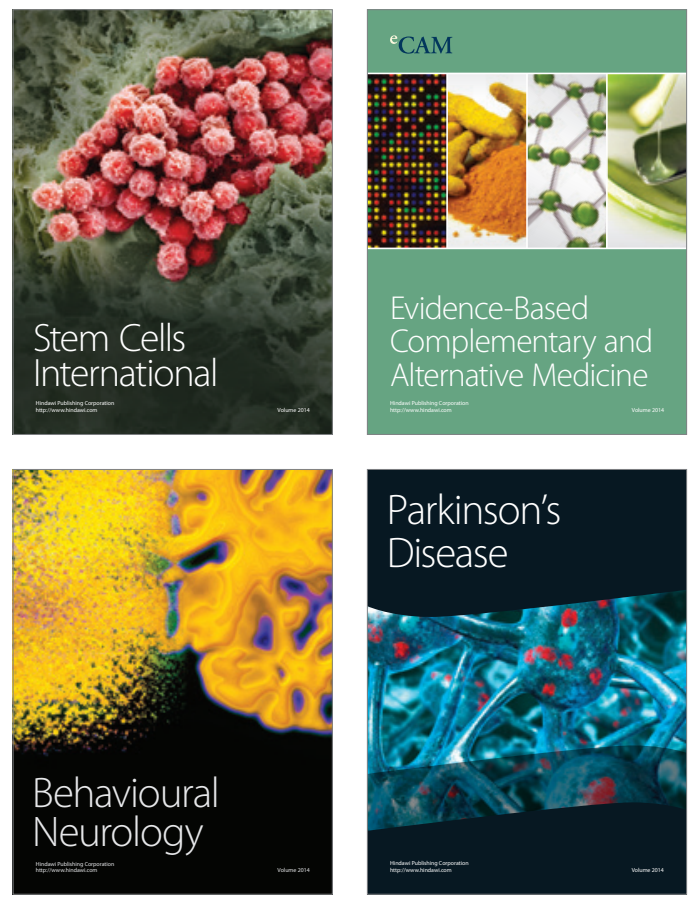
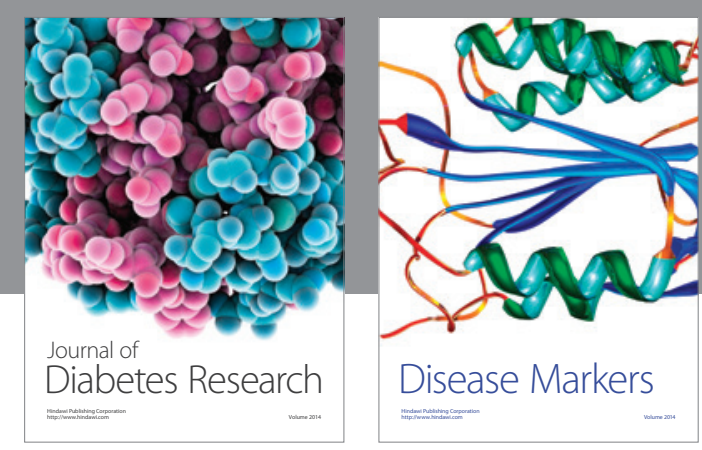

Disease Markers
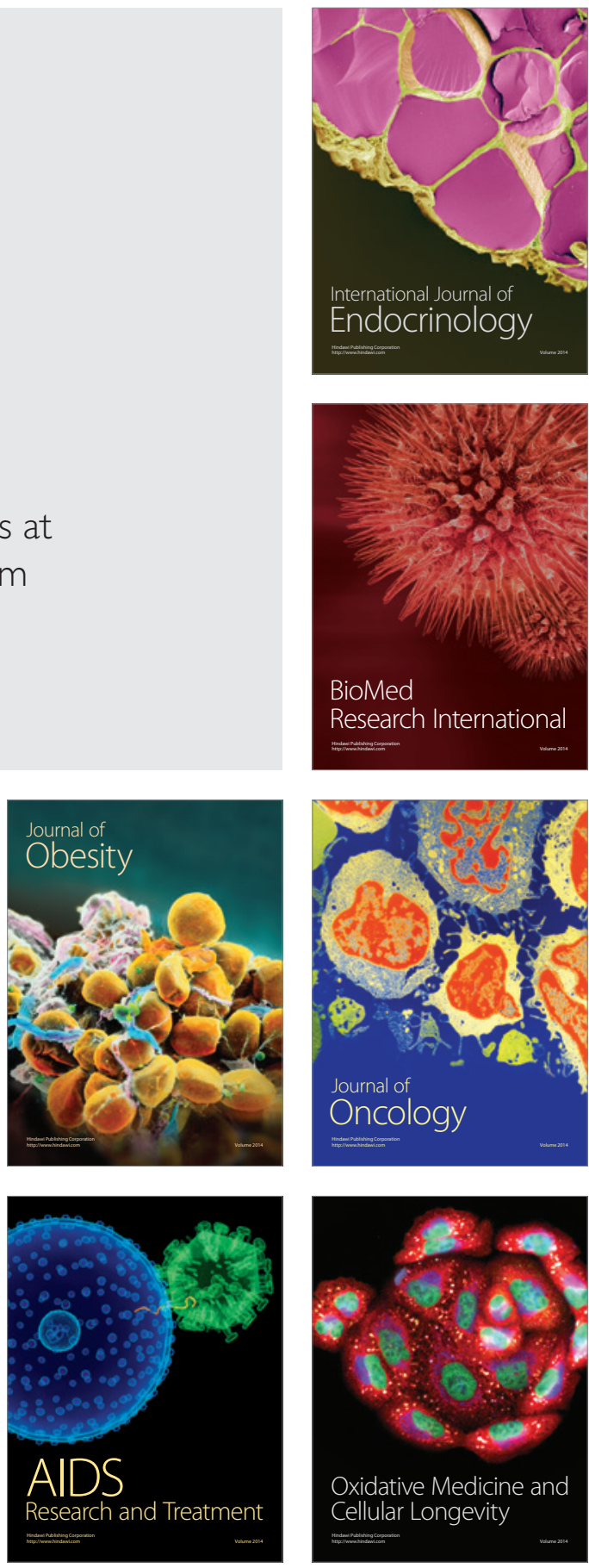